\title{
Phase Diagram of Binary Alloy Nanoparticles under High Pressure
}

\author{
Han Gyeol Kim ${ }^{1}$, Joonho Lee ${ }^{1, *}$ and Guy Makov ${ }^{2, *(D)}$ \\ 1 Department of Materials Science and Engineering, Korea University, Seoul 02841, Korea; \\ pureblue7@korea.ac.kr \\ 2 Department of Materials Engineering, Ben-Gurion University of the Negev, Beer-Sheva 84105, Israel \\ * Correspondence: joonholee@korea.ac.kr (J.L.); makovg@bgu.ac.il (G.M.)
}

check for updates

Citation: Kim, H.G.; Lee, J.; Makov, G. Phase Diagram of Binary Alloy Nanoparticles under High Pressure. Materials 2021, 14, 2929. https:// doi.org/10.3390/ma14112929

Academic Editors: Frank Czerwinski and Ştefan Ţălu

Received: 19 March 2021

Accepted: 24 May 2021

Published: 29 May 2021

Publisher's Note: MDPI stays neutral with regard to jurisdictional claims in published maps and institutional affiliations.

Copyright: (c) 2021 by the authors. Licensee MDPI, Basel, Switzerland. This article is an open access article distributed under the terms and conditions of the Creative Commons Attribution (CC BY) license (https:// creativecommons.org/licenses/by/ $4.0 /)$.
Abstract: CALPHAD (CALculation of PHAse Diagram) is a useful tool to construct phase diagrams of various materials under different thermodynamic conditions. Researchers have extended the use of the CALPHAD method to nanophase diagrams and pressure phase diagrams. In this study, the phase diagram of an arbitrary A-B nanoparticle system under pressure was investigated. The effects of the interaction parameter and excess volume were investigated with increasing pressure. The eutectic temperature was found to decrease in most cases, except when the interaction parameter in the liquid was zero and that in the solid was positive, while the excess volume parameter of the liquid was positive. Under these conditions, the eutectic temperature increased with increasing pressure.

Keywords: CALPHAD; nanoparticles; pressure; phase diagrams; eutectic point

\section{Introduction}

During the last several decades, computational modeling of phase diagrams using the CALPHAD (CALculation of PHAse Diagrams) method has been applied to various systems under extreme conditions of small particles and high pressures [1-62]. Weissmüller first suggested a simple CALPHAD-type thermodynamic model of nanostructures $[1,2]$. Later, Tanaka et al. incorporated the Butler equation into the thermodynamic modeling of nanoparticles to evaluate the surface effect [3-5]. Park and Lee proposed CALPHAD-type thermodynamic equations, which can be used directly in commercial thermodynamic software [6,7]. This method has been extended to nanowire and nanofilm systems [8]. Recently, Sim and Lee successfully assessed the phase diagrams of nanoparticles containing intermetallic compounds [9]. Application of this model to pure metallic nanoparticles has been validated experimentally and theoretically [10-19]. The validity of this model has also been confirmed through phase diagram studies of various alloy nanoparticle systems (Ag-Au [6,8,20-22], Ag-Co [23], Ag-Cu [24-26], Ag-Sn [9,27-30], Au-Cu [31], Au-Pt [32], Bi-Cd [33], Bi-Sn [34,35], Cu-Ni [36-41], Cu-Pt [42], In-Sb [43], Ni-Sn [44], Si-Ge [45,46], etc.). This model has been extended to phase diagram studies on ceramic nanoparticles [47-50] and aerosol nanoparticles [51]. Studies of nanowires in the frame of the CALPHAD method can be found in the literature [52-55]. On the other hand, phase diagrams of various materials under high pressure have also been assessed using the framework of the CALPHAD method [56-59]. Ben Shalom et al. reported the pressure diagram of the Ga-In system calculated with bulk thermodynamic data and highly accurate sound velocity and density data [56]. Similar works have been carried out for various systems, such as Bi-Sn [57,58], Bi-Sb [58,59], and Pb-Sn [58,59]. These studies demonstrate that this methodology can be applied to systems with high pressures of up to several GPa. Although obtaining the phase diagram is essential when designing new materials and processes, experimental determination of the phase diagram under extreme conditions remains challenging [60]. 
On the other hand, several researchers have reported on the phase stability of nanoparticles under high pressure, which differs from that of bulk materials under ambient pressure. Tolbert and Alivisatos investigated the size dependence of the phase transition of CdSe nanoparticles under high pressure [61]. They reported that the phase transformation pressure from wurtzite and zinc blende to rock-salt structure changed from 2.5-3.0 GPa for bulk material to $6.3 \mathrm{GPa}$ for $4.4 \mathrm{~nm}$ nanoparticles. Qadri et al. reported that the transition pressure of $\mathrm{PbS}$ nanoparticles increases with a decrease in particle size [62]. Wang et al. found that the phase transition of $30 \mathrm{~nm} \mathrm{TiO} 2$ nanoparticles from the anatase and rutile mixture to baddeleyite structure occurs at $8.7 \mathrm{GPa}$, whereas bulk $\mathrm{TiO}_{2}$ at $2-5 \mathrm{GPa}$ transitions from anatase to columbite $\alpha-\mathrm{PbO}_{2}$-type structure and a successive phase transformation to baddeleyite structure occurs at 12-15 GPa [63]. Daou et al. synthesized $\mathrm{Fe}_{3} \mathrm{O}_{4}$ nanoparticles using a hydrothermal process in which high pressure was applied at elevated temperatures [64]. Hsu et al. synthesized wurtzite- $\mathrm{ZnO}$ nanoparticles under pressures as high as 2 GPa [65]. In order to understand the phase stability of nanoparticles at high pressure and high temperature, the phase diagram of nanoparticles should be established at high pressure. However, due to the experimental difficulties of performing phase stability measurements under extreme conditions, it is not easy to establish a thermodynamic database for such phase diagram calculations. Nevertheless, it would be helpful to examine the effects of changes in thermodynamic and thermophysical properties on the phase stability of nanosystems under high pressure based on a simplified system.

In this study, the phase diagram of spherical nanoparticles under high pressure is examined using a simplified arbitrary A-B binary regular solution model, which was suggested by Lee et al. [7]. Those authors investigated the effects of the interaction parameter on the phase stability of binary alloy nanoparticle systems using the simplified regular solution model. They found that the shape of the phase diagram significantly changed as the particle size decreased when the solid interaction parameter was positive and the liquid interaction parameter was less than or equal to zero, demonstrating a eutectic point. When the particle size decreased, the eutectic temperature slightly decreased, and the eutectic composition moved in the direction of the pure substance with a lower melting point. In the other cases, the melting points and liquidus temperatures of nanoparticles decreased continuously when the particle size decreased across the entire composition range. Recently, this regular solution model was also used to examine the effects of the interaction parameter and the excess volume on the pressure phase diagram [66]. Here, it was considered that positive and negative excess volumes corresponded to an increase and decrease in the interaction parameters, respectively. Therefore, in this study, attention is paid to binary alloy nanoparticle systems with a eutectic point. The effects of size and pressure were investigated while controlling the interaction parameter and the excess volume. In a real case, it is necessary to consider phase separation in a nanoparticle, as the presence of a solid-solid or solid-liquid interface may affect the phase stability of the nanoparticle. Thus, the present model is only validated when the two phases have the same curvature and share a facet interface. This assumption may not alter the direction of changes in the phase diagram, but the extent to which that holds true is not known [7].

\section{Theory and Model}

\subsection{Effect of Nanoparticle Size}

As the size of a system decreases, the relative contribution of the surface (or interface) to its thermodynamic properties increases. Accordingly, the internal energy $(U)$, enthalpy $(H)$, Helmholtz energy $(A)$, and Gibbs energy $(G)$ can be described by Equations (1)-(4).

$$
\begin{aligned}
& d U=T d S-P d V+\sum_{i} \mu_{i} d n_{i}+\sigma d s \\
& d H=T d S+V d P+\sum_{i} \mu_{i} d n_{i}+\sigma d s
\end{aligned}
$$




$$
\begin{aligned}
& d A=-S d T-P d V+\sum_{i} \mu_{i} d n_{i}+\sigma d s \\
& d G=-S d T+V d P+\sum_{i} \mu_{i} d n_{i}+\sigma d s
\end{aligned}
$$

where $S$ is the entropy, $T$ is the temperature, $P$ is the pressure, $V$ is the volume, $n_{i}$ is the number of moles of $i, \mu_{i}$ is the chemical potential of $i, s$ is the surface area, and $\sigma$ is the surface tension. In this paper, it is simply assumed that the contribution of interfacial energy to thermodynamic properties is negligible. From the definition, the chemical potential of $i$ can be described by Equation (5).

$$
\mu_{i}=\left(\frac{\partial U}{\partial n_{i}}\right)_{S, V, n_{j}, S}=\left(\frac{\partial H}{\partial n_{i}}\right)_{S, P, n_{j}, S}=\left(\frac{\partial A}{\partial n_{i}}\right)_{T, V, n_{j}, S}=\left(\frac{\partial G}{\partial n_{i}}\right)_{T, P, n_{j}, S}
$$

It is difficult to fix the entropy and volume for a nanoparticle system. Therefore, the chemical potential is generally defined from the Gibbs energy. Here, it should be noted that all of the variables are independent. However, this hypothesis is not valid in a nanoparticle system because the surface area $(s)$ is affected by the change in mole number $\left(n_{i}\right)$. Thus, an infinitesimal change in the surface area $(d s)$ should be suggested by a function of the mole number $\left(d n_{i}\right)$ [8]. For simplicity of calculation, a spherical nanoparticle is assumed. For an isotropic spherical particle, the volume and the surface of the particle can be described with respect to the particle's radius ( $r$ ) by Equations (6) and (7), respectively.

$$
\begin{gathered}
V=\frac{4}{3} \pi r^{3} \\
s=4 \pi r^{2}=\frac{3 V}{r}
\end{gathered}
$$

Differentiating Equations (6) and (7) with respect to $r$, the volume and the surface changes are given by Equations (8) and (9), respectively.

$$
\begin{gathered}
d V=4 \pi r^{2} d r \\
d s=8 \pi r d r
\end{gathered}
$$

Incorporating Equations (8) and (9), $d s$ can be approximated as a function of $d n_{i}$ (Equation (10)).

$$
d s=\frac{2}{r} d V=\frac{2}{r} \sum V_{i} d n_{i}
$$

Then, Equation (4) is replaced by Equation (11).

$$
d G=-S d T+V d P+\sum_{i}\left(\mu_{i}+\frac{2 \sigma V_{i}}{r}\right) d n_{i}
$$

Consequently, the chemical potential of $i$ of a nanoparticle system is expressed by Equation (12) [8].

$$
\mu_{i}^{N P}=\left(\frac{\partial G}{\partial n_{i}}\right)_{T, P, n_{j}}=\mu_{i}^{B u l k}+\frac{2 \sigma V_{i}}{r}
$$

When it is assumed instead that the surface area $(s)$ and the mole number $\left(n_{i}\right)$ are independent variables, the second term of Equation (12) can be written as $3 \sigma V_{i} / r$ [8].

For simplicity, let us consider an A-B binary alloy nanoparticle system. It is also assumed that the nanoparticle is isotropic spherical. Then, the molar Gibbs energy of the nanoparticle system is expressed by Equation $(13)[3,4]$.

$$
G_{m}^{N P}=G_{m}+G^{N P, \text { surf. }}
$$




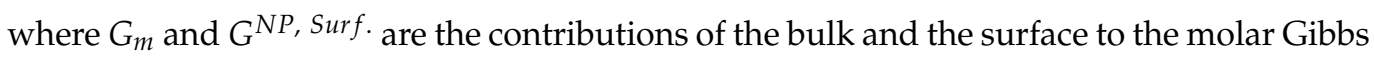
energy, respectively. From the analogy of bulk thermodynamic description, Equation (13) can be described by Equation (14) [8].

$$
G_{m}^{N P}=X_{A} G_{A}^{o N P}+X_{B} G_{B}^{o N P}+R T\left(X_{A} \ln X_{A}+X_{B} \ln X_{B}\right)+G^{E x, N P}
$$

where $X_{i}$ is the mole fraction of $i(=A, B), G_{i}^{o N P}$ is the standard molar Gibbs energy of the nanoparticle of pure $i, R$ is the gas constant, $T$ is the temperature and $G^{E x, N P}$ is the excess Gibbs energy of the nanoparticle system [8].

$$
\begin{gathered}
G_{i}^{o N P}=G_{i}^{o}+\frac{2 \sigma_{i} V_{i}}{r} \\
G^{E x, N P}=G_{m}+\frac{2 \sigma V}{r}-\left(X_{A} G_{A}^{o N P}+X_{B} G_{B}^{o N P}+R T\left(X_{A} \ln X_{A}+X_{B} \ln X_{B}\right)\right)
\end{gathered}
$$

where $\sigma$ is the surface tension of the alloy, $V$ is the molar volume of the alloy, $r$ is the radius of the nanoparticle, $\sigma_{i}$ is the surface tension of pure $i$, and $V_{i}$ is the molar volume of pure $i$. Assuming a regular solution, the excess Gibbs energy of the nanoparticle system can be simplified to Equation (17) using the interaction parameter $\Omega^{N P}[1,2,19]$.

$$
G^{E x, N P}=\Omega^{N P} X_{A} X_{B}=X_{A} X_{B} \sum L_{k}^{N P}\left(X_{A}-X_{B}\right)^{k}
$$

where $L_{k}{ }^{N P}(k=0,1,2, \ldots)$ is the Redlich-Kister constant of the nanoparticle system.

The surface tension of the A-B alloy is calculated by Butler's equation.

$$
\begin{aligned}
\sigma & =\sigma_{A}+\frac{R T}{A_{A}} \ln \left(\frac{X_{A}^{s}}{X_{A}^{b}}\right)+\frac{\Omega^{\text {Bulk }}}{A_{A}}\left(\beta\left(X_{B}^{s}\right)^{2}-\left(X_{B}^{b}\right)^{2}\right) \\
& =\sigma_{B}+\frac{R T}{A_{B}} \ln \left(\frac{X_{B}^{s}}{X_{B}^{b}}\right)+\frac{\Omega^{\text {Bulk }}}{A_{B}}\left(\beta\left(X_{A}^{s}\right)^{2}-\left(X_{A}^{b}\right)^{2}\right)
\end{aligned}
$$

where $\sigma_{i}$ is the surface tension of a pure element, $A_{i}$ is the molar surface area of pure $i$ $\left(A_{i}=1.091 N_{A}{ }^{1 / 3} V_{i}^{2 / 3}\right.$ where $N_{A}$ is Avogadro's number and $V_{i}$ is the molar volume of pure $i), X_{i}^{s}$ is the surface composition of $i, X_{i}^{b}$ is the bulk composition of $i, \Omega^{\text {Bulk }}$ is the bulk interaction parameter, and $\beta$ is the parameter corresponding to the ratio of the coordination number in the surface to that in bulk. Park and Lee showed that the values of $\beta$ for liquid metals and solid metals are 0.85 and 0.84 , respectively [6].

The molar volume of the alloy is calculated by Equation (19).

$$
V=X_{A} V_{A}+X_{B} V_{B}+V^{E x}=X_{A} V_{A}+X_{B} V_{B}+V_{A, B} X_{A} X_{B}
$$

where $V^{E x}$ is the excess volume and $V_{A, B}$ is the excess volume parameter. In this study, it is assumed that $V_{A, B}$ for the solid is zero, because the excess volume of a liquid is generally much larger than that of the corresponding solid.

\subsection{Effect of Pressure on Thermodynamic Equations}

The molar Gibbs energy of a system under high pressure, $G_{m}^{P}$, is expressed by Equation (20):

$$
G_{m}^{P}=G_{m}+\left(\frac{\partial G}{\partial P}\right)_{P \rightarrow 0} P=G_{m}+V P
$$

where $G_{m}$ is the molar Gibbs energy of pure $i$ under atmospheric pressure, $V$ is the molar volume of a solution, and $P$ is the pressure.

On the other hand, the molar Gibbs energy of a system under high pressure can be rewritten by Equation (21).

$$
G_{m}^{P}=X_{A} G_{A}^{P}+X_{B} G_{B}^{P}+R T\left(X_{A} \ln X_{A}+X_{B} \ln X_{B}\right)+G^{E x, P}
$$


where $G_{i}^{P}$ is the molar Gibbs energy of pure $i$ under pressure $P$ and $G^{E x, P}$ is the excess Gibbs energy under pressure $P . G_{i}^{P}$ and $G^{E x, P}$ are given by Equations (22) and (23), respectively.

$$
G_{i}^{P}=G_{i}^{o}+\left(\frac{\partial G_{i}}{\partial P}\right)_{P \rightarrow 0} P=G_{i}^{o}+V_{i} P
$$

where $G_{i}^{o}$ is the standard molar Gibbs energy of pure $i$ and $V_{i}$ is the molar volume of pure $i$ under atmospheric pressure.

$$
G^{E x, P}=G^{E x}+\left(\frac{\partial G^{E x}}{\partial P}\right)_{P \rightarrow 0} P=G^{E x}+V^{E x} P
$$

where $G^{E x}$ is the bulk excess Gibbs energy under atmospheric pressure and $V^{E x}$ is the excess volume, which can be expressed by Equation (24).

$$
\begin{aligned}
V^{E x} & =V-V_{\text {ideal }}=V-\left(X_{A} V_{A}+X_{B} V_{B}\right)=\frac{M}{\rho}-\left(X_{A} \frac{M_{A}}{\rho_{A}}+X_{B} \frac{M_{B}}{\rho_{B}}\right) \\
& =\left(\frac{\partial G^{E x}}{\partial P}\right)_{p \rightarrow 0}=X_{A} X_{B} \sum\left(\frac{\partial L_{k}^{P}}{\partial P}\right)_{p \rightarrow 0}\left(X_{A}-X_{B}\right)^{k}
\end{aligned}
$$

where $V_{\text {ideal }}$ is the hypothetical volume of the alloy by ideal mixing, $M$ is the molar mass of the alloy, $\rho$ is the density of the alloy, $M_{i}$ is the molar mass of pure $i$, and $\rho_{i}$ is the density of pure $i$ [56-59]. Here, it is assumed that the excess volume is constant at high pressures up to several GPa.

Finally, the excess Gibbs energy of a system under high pressure can be simplified to Equation (25) using the interaction parameter under high pressure $\Omega^{P}$.

$$
G^{E x, P}=G^{E x}+V^{E x} P=\Omega^{P} X_{A} X_{B}=X_{A} X_{B} \sum L_{k}^{P}\left(X_{A}-X_{B}\right)^{k}
$$

\subsection{Thermodynamic Equations of Nanoparticles under High Pressure}

Now, the effects of particle size and pressure can be merged into Equation (26).

$$
G_{m}^{N P, P}=X_{A} G_{A}^{o N P, P}+X_{B} G_{B}^{o N P, P}+R T\left(X_{A} \ln X_{A}+X_{B} \ln X_{B}\right)+G^{E x, N P, P}
$$

The standard molar Gibbs energy of the nanoparticle of pure $i$ under pressure $P$ is expressed by Equation (27).

$$
G_{i}^{o N P, P}=G_{i}^{o}+\frac{2 \sigma_{i} V_{i}}{r}+V_{i} P
$$

The excess Gibbs energy is expressed by Equation (28).

$$
G^{E x, N P, P}=G^{E x, N P}+V^{E x} P=X_{A} X_{B} \sum L_{k}^{N P, P}\left(X_{A}-X_{B}\right)^{k}
$$

\subsection{Phase Equilibria Model}

In this study, a regular solution model for arbitrary A-B systems with a eutectic point is considered. The melting points of the end-members, $\mathrm{A}$ and $\mathrm{B}$, are assumed to be 1200 and $800 \mathrm{~K}$, respectively. When pure solid $i$ is taken as the standard state (assuming that $G_{i(s)}^{o}=0$ ), the Gibbs energy of pure liquid $i$ is assumed to be expressed by Equation (29) [7].

$$
G_{i(L)}^{o}=S_{m, i}\left(T_{m, i}-T\right)
$$

where the melting point entropy of pure $i, S_{m, i}$, is assumed to be $8.8 \mathrm{~J} \mathrm{~K}^{-1} \mathrm{~mol}^{-1}$ according to Richard's rule [67]. Here, $T_{m, i}$ is the melting point of pure $i$.

A systematic study by Lee et al. on the shape of phase diagrams of a simple binary alloy system reported that a eutectic point was observed when the excess Gibbs energy of a liquid was zero or negative while the excess Gibbs energy of the solid was positive [7]. 
Therefore, in the present study, $G_{(L)}^{E x}$ is assumed to be $-15,000 X_{A} X_{B}$ and $0 \mathrm{~J} \mathrm{~mol}^{-1}$, while $G_{(s)}^{E x}$ is $15,000 X_{A} X_{B} \mathrm{~J} \mathrm{~mol}^{-1}$.

The surface tensions of the pure liquid and solid are approximated by Equations (30) and (31), respectively [7].

$$
\begin{aligned}
& \sigma_{i(l)}=0.00075 T_{m, i}-0.0001\left(T-T_{m, i}\right)\left(\mathrm{N} \mathrm{m}^{-1}\right) \\
& \sigma_{i(s)}=0.00087 T_{m, i}-0.0001\left(T-T_{m, i}\right)\left(\mathrm{N} \mathrm{m}^{-1}\right)
\end{aligned}
$$

Assuming $4 \%$ volume expansion upon melting and a temperature coefficient of $10^{-4} \mathrm{~K}^{-1}$, the molar volume of the pure solid and liquid can be expressed by Equations (32) and (33), respectively [7].

$$
\begin{gathered}
V_{i(s)}=1.00 \times 10^{-5}\left(\mathrm{~m}^{3} \mathrm{~mol}^{-1}\right) \\
V_{i(l)}=1.04 \times 10^{-5} \times\left\{1+10^{-4}\left(T-T_{i, m}\right)\right\}\left(\mathrm{m}^{3} \mathrm{~mol}^{-1}\right)
\end{gathered}
$$

The excess volume parameter of the solid is assumed to be zero $\left(V_{A, B(s)}=0\right)$, whereas that of the liquid $\left(V_{A, B(l)}\right)$ is $-10^{-6}, 0$, and $10^{-6} \mathrm{~m}^{3} \mathrm{~mol}^{-1}$.

\section{Results and Discussion}

\subsection{Variations in the Shape of the Phase Diagram}

Phase diagrams were calculated by Gibbs energy minimization with FactSage software $[68,69]$. Figure 1 shows the phase diagrams of bulk material, nanoparticles, and nanoparticles under a pressure of $2 \mathrm{GPa}$. Here, the interaction parameter of bulk solid under atmospheric pressure was $+15 \mathrm{~kJ} \mathrm{~mol}^{-1}$, whereas that of bulk liquid under atmospheric pressure was $-15 \mathrm{~kJ} \mathrm{~mol}^{-1}$. The interaction parameter could be modified by a size effect or pressure effect. The size of each nanoparticle was assumed to be $r=5 \mathrm{~nm}$. The excess volume parameter for liquid $\left(V_{A, B(l)}\right)$ varied between $-10^{-6}, 0$, and $+10^{-6} \mathrm{~m}^{3} \mathrm{~mol}^{-1}$. Notably, the melting points of the pure substances (A and B) decreased for nanoparticles vs. bulk material, while it increased when high pressure was applied to the nanoparticles. On the other hand, the eutectic point decreased for nanoparticles, and it decreased further when high pressure was applied to the system. The extent of the reduction in the eutectic temperature became greater when the excess volume parameter was negative. Makov et al. demonstrated that the eutectic temperature of bulk binary alloys decreases as the solid interaction parameter increases or the liquid interaction parameter decreases [66]. The same authors also found that the effects of positive and negative excess volumes at high pressure correspond to the increase and decrease in the interaction parameters, respectively. Since the excess volume of the solid is negligible compared to that of the liquid, a negative excess volume of liquid in the present study results in the same effect as a decrease in the liquid interaction parameter. Consequently, the eutectic temperature of the nanoparticles decreased with increasing pressure.

Figure 2 shows the phase diagrams when the interaction parameter of the solid was $+15 \mathrm{~kJ} \mathrm{~mol}^{-1}$, while that of the liquid was $0 \mathrm{~kJ} \mathrm{~mol}^{-1}$. The eutectic temperature generally increased in comparison to the calculation results shown in Figure 1. When the excess volume parameter for liquid was $-10^{-6} \mathrm{~m}^{3} \mathrm{~mol}^{-1}$, the eutectic temperature decreased with the change from bulk to nanoparticles and nanoparticles under high pressure. However, when the excess volume parameter of the liquid was $+10^{-6} \mathrm{~m}^{3} \mathrm{~mol}^{-1}$, the eutectic temperature decreased with the change from bulk to nanoparticles, whereas it increased when high pressure was applied to the nanoparticles. As described above, an increase in the liquid interaction parameter from $-15 \mathrm{~kJ} \mathrm{~mol}^{-1}$ to $0 \mathrm{~kJ} \mathrm{~mol}^{-1}$ yielded an increase in eutectic temperature. 

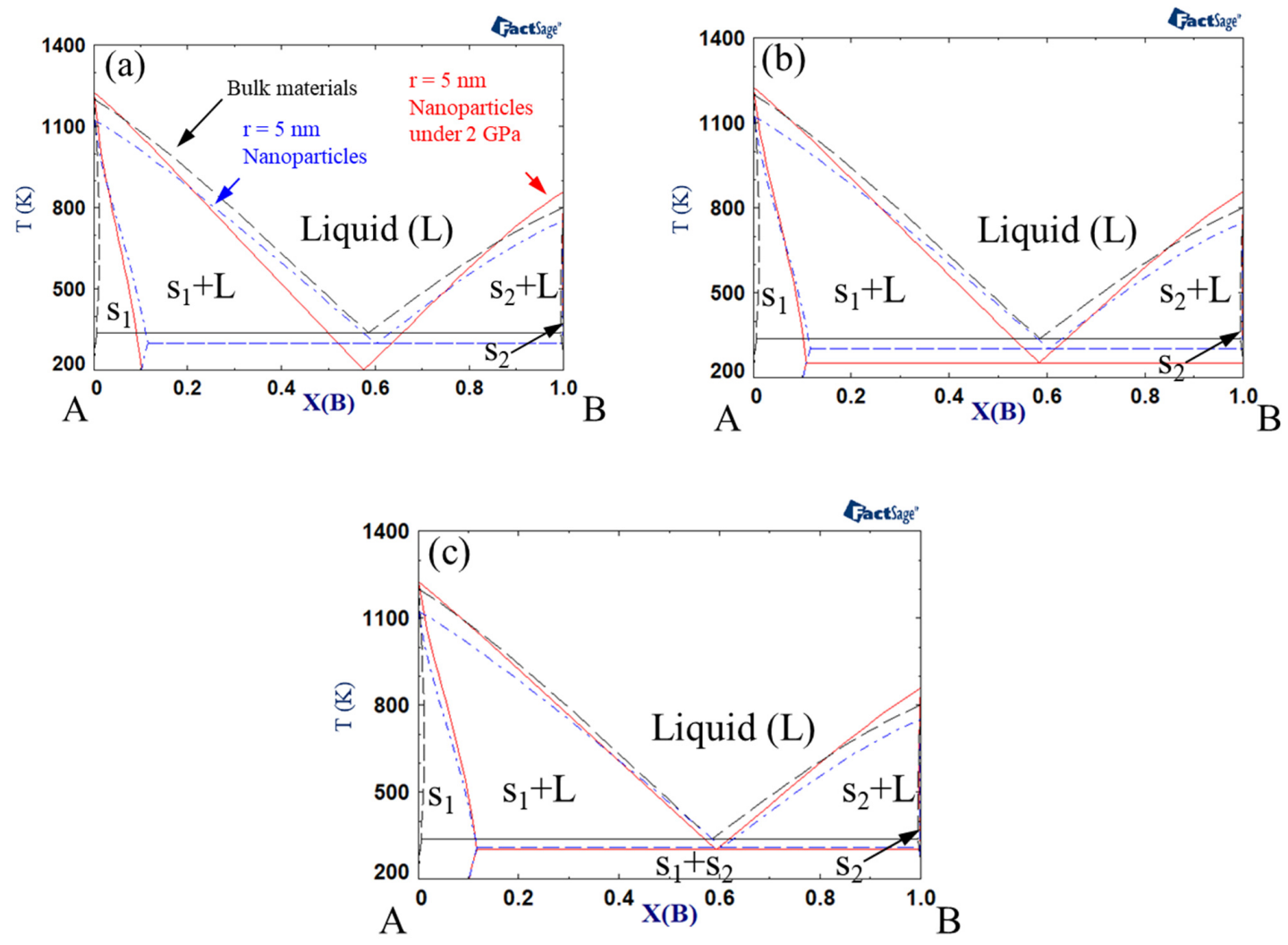

Figure 1. A-B phase diagram of each case (black dashed line indicates bulk material; blue dash-dotted line indicates $5 \mathrm{~nm}$ radius nanoparticles, red solid line indicates $5 \mathrm{~nm}$ radius nanoparticles under $2 \mathrm{GPa}$ ): $\Omega_{S}=15 \mathrm{~kJ} / \mathrm{mol}, \Omega_{L}=-15 \mathrm{~kJ} / \mathrm{mol}$, (a) $V^{E x}=-1 \mathrm{~cm}^{3} / \mathrm{mol}$, (b) $V^{E x}=0 \mathrm{~cm} / \mathrm{mol}$, (c) $V^{E x}=1 \mathrm{~cm}^{3} / \mathrm{mol}$.
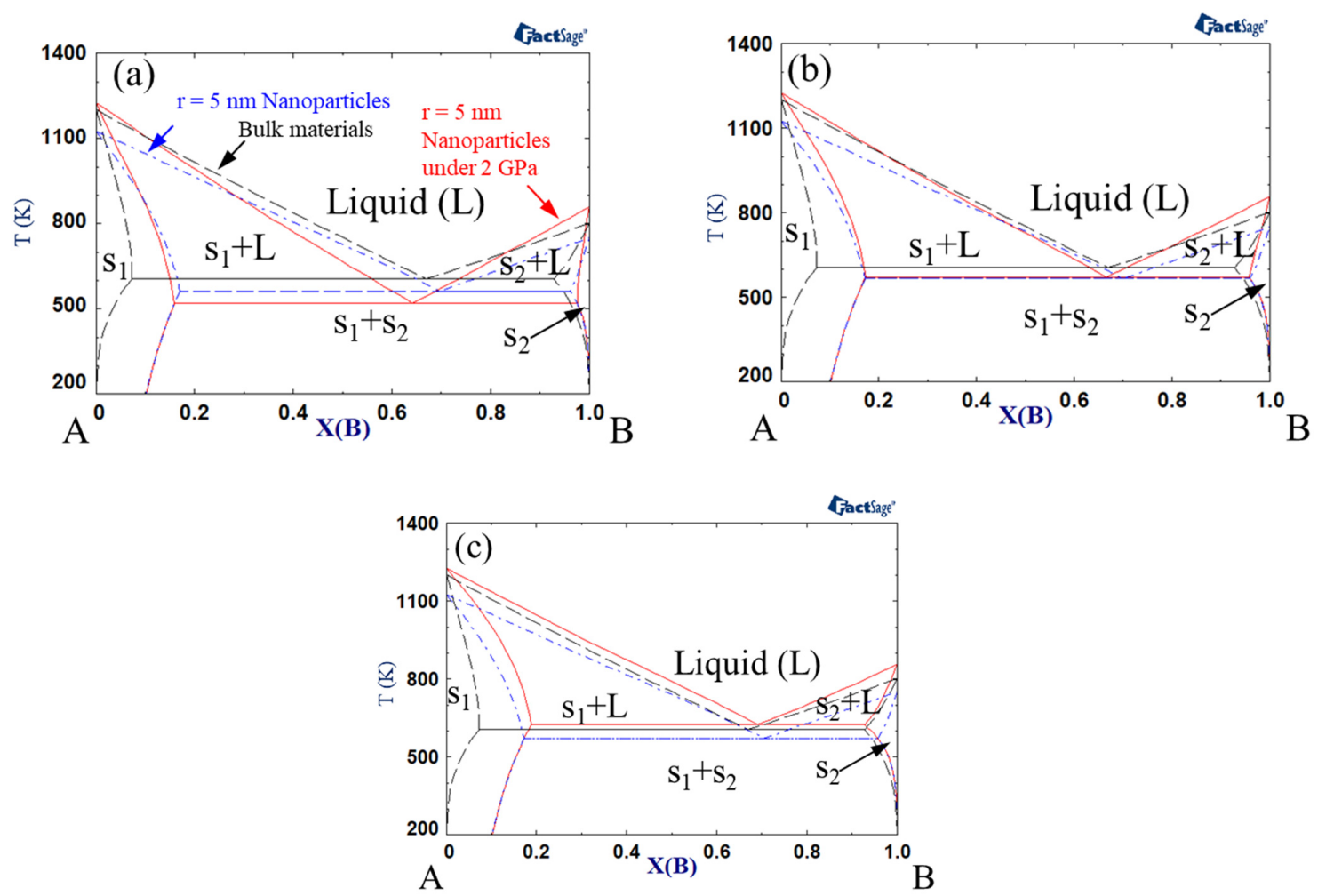

Figure 2. A-B phase diagram of each case (black dashed line indicates bulk material, blue dash-dotted line indicates $5 \mathrm{~nm}$ radius nanoparticles, red solid line indicates $5 \mathrm{~nm}$ radius nanoparticles under $2 \mathrm{GPa}$ ): $\Omega_{S}=15 \mathrm{~kJ} / \mathrm{mol}, \Omega_{L}=0 \mathrm{~kJ} / \mathrm{mol}$, (a) $V^{E x}=-1 \mathrm{~cm}^{3} / \mathrm{mol}$, (b) $V^{E x}=0 \mathrm{~cm}^{3} / \mathrm{mol}$, (c) $V^{E x}=1 \mathrm{~cm}^{3} / \mathrm{mol}$. 


\subsection{Variations in the Eutectic Points}

Figure 3a shows the relationship between eutectic composition and eutectic temperature when the interaction parameter of the solid is $+15 \mathrm{~kJ} \mathrm{~mol}^{-1}$ and that of the liquid is $-15 \mathrm{~kJ} \mathrm{~mol}^{-1}$. For the change from bulk to nanoparticles, the eutectic composition moves to the direction of the low melting temperature element, B. When high pressure is applied, the eutectic composition moves back in the direction of the high melting temperature element, A. The changes in temperature and composition are more significant when the excess volume parameter of the liquid is negative.
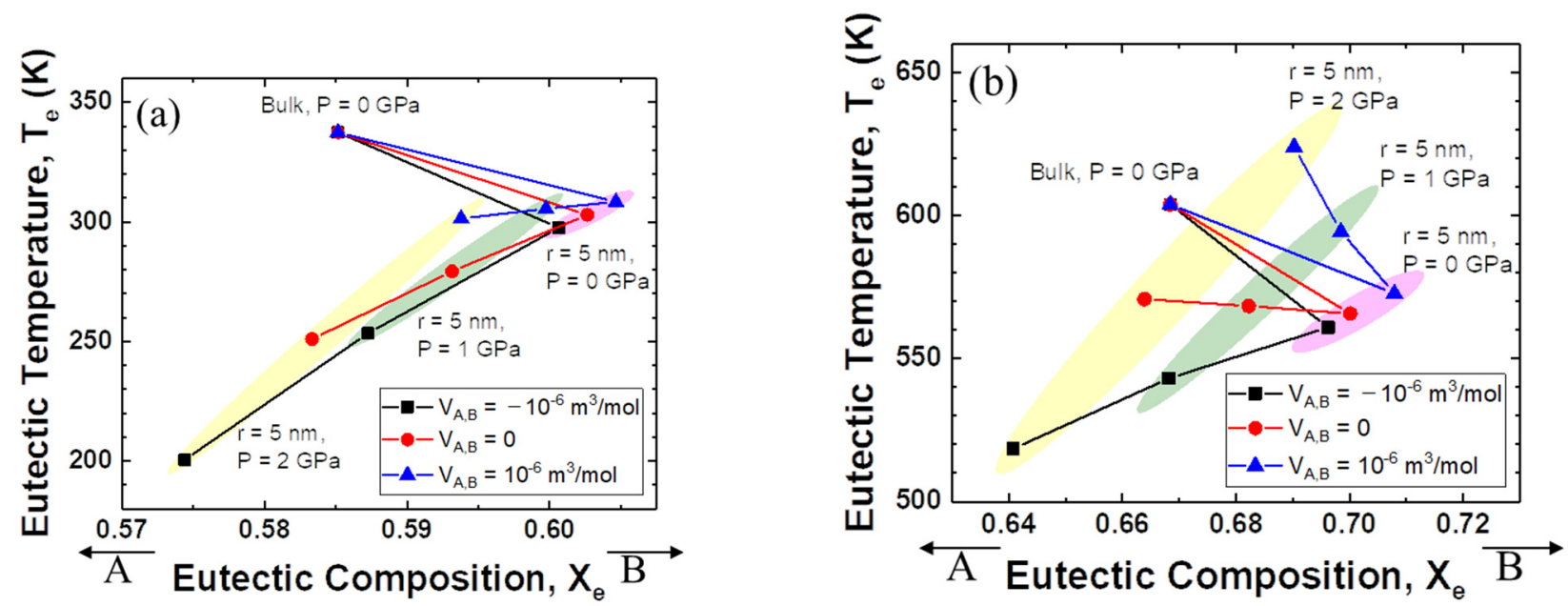

Figure 3. Eutectic temperature and eutectic composition of A-B phase diagram of each case (negative excess Gibbs energy parameter of liquid/zero excess Gibbs energy parameter of liquid): (a) $\Omega_{S}=15 \mathrm{~kJ} / \mathrm{mol}, \Omega_{L}=-15 \mathrm{~kJ} / \mathrm{mol},(\mathbf{b}) \Omega_{S}=15 \mathrm{~kJ} / \mathrm{mol}$, $\Omega_{L}=0 \mathrm{~kJ} / \mathrm{mol}$.

Figure $3 \mathrm{~b}$ shows more interesting results. The direction of movement of the eutectic composition is the same as shown in Figure 3a. However, the change in the eutectic temperature depends on the sign of the excess volume parameter for liquid. When the excess volume parameter has a negative value, the eutectic temperature decreases for the change from bulk to nanoparticles, and for the change from atmospheric pressure to high pressure. On the other hand, when the excess volume parameter is zero, the eutectic temperature does not change much as the pressure increases. Surprisingly, when the excess volume parameter is positive, the eutectic temperature rises rapidly with increasing applied pressure.

Figure 4 illustrates the relationship between the eutectic composition and the eutectic temperature when the excess volume parameters are fixed at $-10^{-6}, 0$, and $+10^{-6} \mathrm{~m}^{3} \mathrm{~mol}^{-1}$. It is evident that the eutectic point of the system with a negative interaction parameter for liquid is much lower than that of the ideal mixing alloy. Significantly, the direction of the eutectic temperature change is very negative when the excess volume parameter is negative, whereas the eutectic temperature is pushed to a higher value as the excess volume parameter becomes positive. 

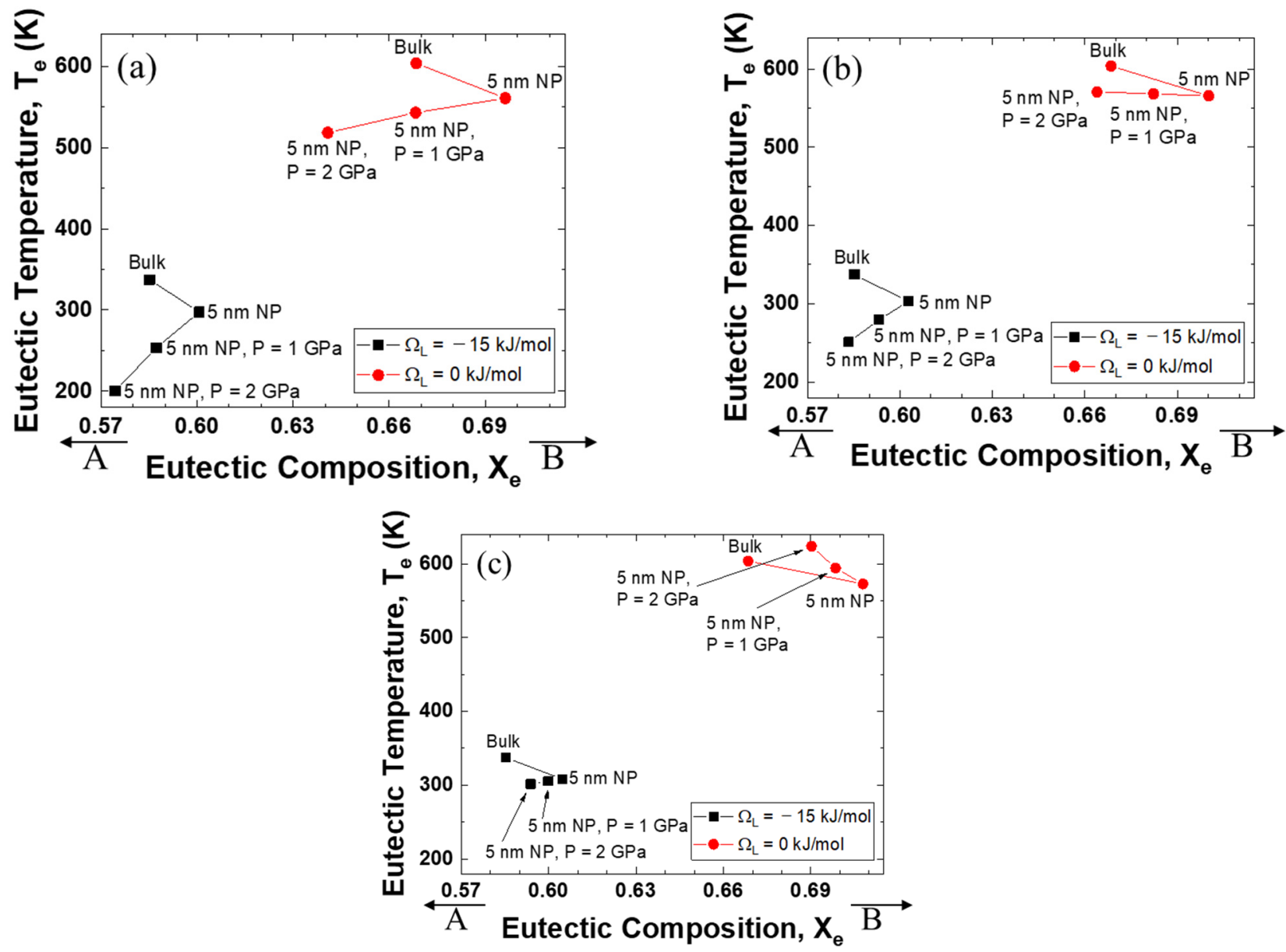

Figure 4. Eutectic temperature and eutectic composition of A-B phase diagram of each case (negative excess volume parameter of liquid/zero excess volume parameter of liquid/positive excess volume parameter of liquid): (a) $V^{E x}=-1 \mathrm{~cm}^{3} / \mathrm{mol}$, (b) $V^{E x}=0 \mathrm{~cm}^{3} / \mathrm{mol}$, (c) $V^{E x}=1 \mathrm{~cm}^{3} / \mathrm{mol}$.

For the end-members (pure substance), the melting point decreases with decreasing particle size because the surface tension is the dominant factor and the surface tension of the solid is greater than that of the liquid (Equation (15)). The melting point of a pure substance generally increases with increasing pressure because the molar volume of the liquid is larger than that of the solid (Equation (20)). Of course, there are several exceptions when the molar volume of liquid is smaller than that of solid, so that the melting point decreases with increasing pressure (e.g., Bi [57]). The effect of pressure is closely related to the excess volume (Equation (23)). In this study, only the effect of excess volume of liquid is discussed, because the excess volume of solid is generally much smaller than that of liquid. When the excess volume of liquid is positive, the excess Gibbs energy increases. Accordingly, the eutectic temperature would be higher than that of a system having zero excess volume. Likely, when the excess volume of liquid is negative, the excess Gibbs energy decreases. Hence, the eutectic point moves to the lower temperature.

Figure 5 shows typical examples of Gibbs energy curves at $338 \mathrm{~K}$ (bulk eutectic temperature under $0 \mathrm{GPa}$ ) for the A-B binary system in Figure 1a. Figure 5 a shows that a single common tangent line can be drawn passing two contact points on the Gibbs energy of the solid (A and I) and one contact point on the Gibbs energy of the liquid (F, eutectic composition). When the particle size becomes $5 \mathrm{~nm}$, the Gibbs energies of both the solid and liquid move upward, yielding two common tangent lines and a narrow liquid region $(\mathrm{E} \sim \mathrm{G})$ (Figure $5 \mathrm{~b}$ ). When a pressure of $2 \mathrm{GPa}$ is applied to the nanoparticles, the Gibbs energies move to much higher positions, forming a wider liquid region (D-H) (Figure 5c). 
This simulation methodology can be used to identify nanoparticle systems which can potentially be used under high pressure.
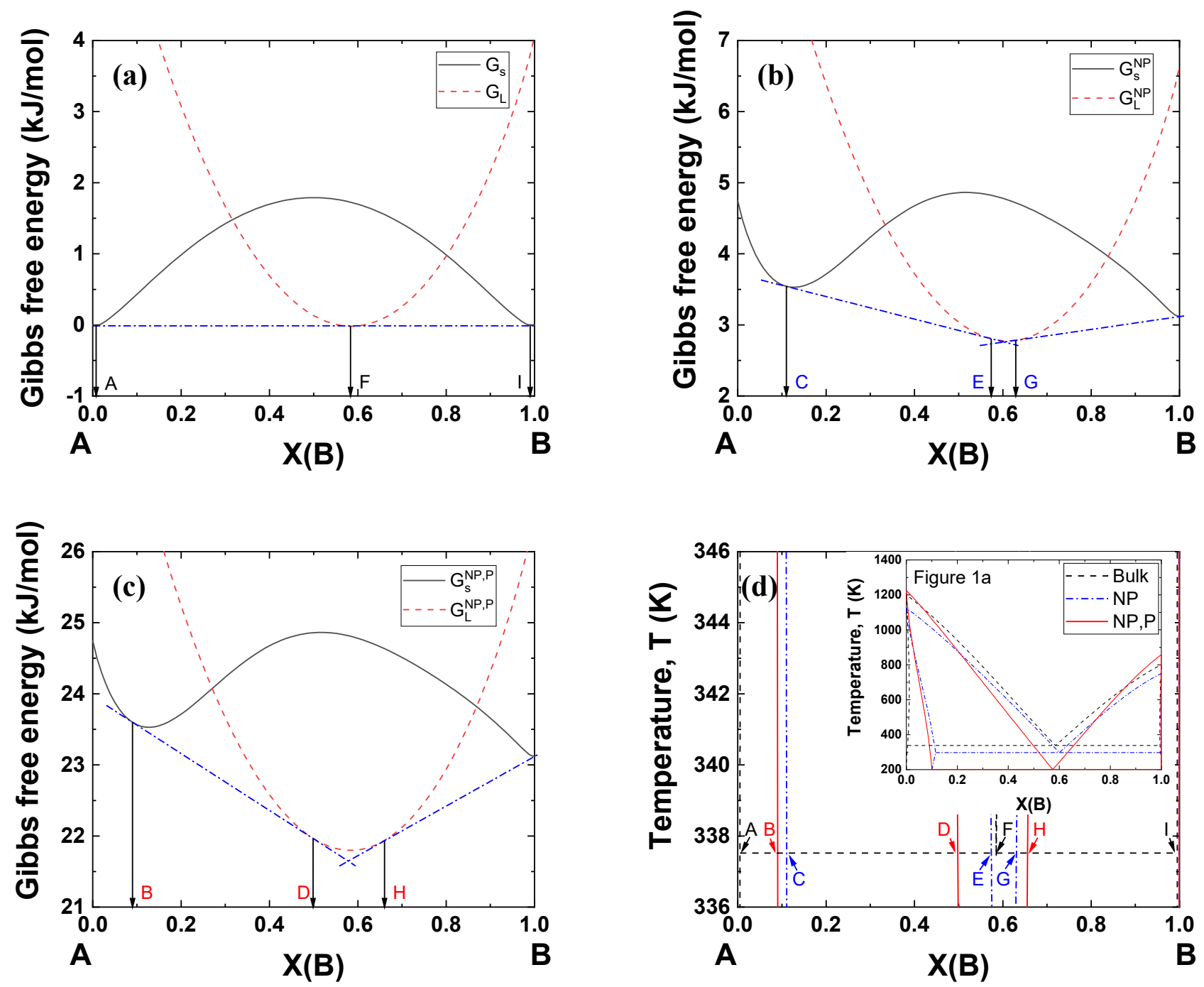

Figure 5. Gibbs energy curve of the A-B binary system at $338 \mathrm{~K}$ in Figure 1a: $V^{E x}=-1 \mathrm{~cm}^{3} / \mathrm{mol}, \Omega_{\mathcal{S}}=15 \mathrm{~kJ} / \mathrm{mol}$, $\Omega_{L}=-15 \mathrm{~kJ} / \mathrm{mol}$. (a) bulk, $P=0 \mathrm{GPa}$, (b) $5 \mathrm{~nm} \mathrm{NP}, P=0 \mathrm{GPa}$ (c) $5 \mathrm{~nm} \mathrm{NP}, P=2 \mathrm{GPa}$. (d) Compositions of the equilibrium phases in Figure 1a.

\section{Conclusions}

The effects of size and pressure on the shape of the phase diagram of nanoparticles were examined using the CALPHAD method for general A-B alloy systems based on a regular solution model. The nanoparticle that was considered had a radius of $5 \mathrm{~nm}$ at pressures of 1 and $2 \mathrm{GPa}$. In order to examine the change in the eutectic point, the interaction parameter of the solid was taken to be $+15 \mathrm{~kJ} \mathrm{~mol}^{-1}$, whereas that of the liquid was -15 or $0 \mathrm{~kJ} \mathrm{~mol}^{-1}$. The excess volume parameter for the solid was assumed to be zero $\left(V_{A, B(s)}=0\right)$, whereas that for the liquid $\left(V_{A, B(l)}\right)$ was taken as $-10^{-6}, 0$, and $+10^{-6} \mathrm{~m}^{3} \mathrm{~mol}^{-1}$. The following conclusions were obtained.

(1) When the interaction parameter of the liquid was $-15 \mathrm{~kJ} \mathrm{~mol}^{-1}$, the eutectic temperature decreased during the change from bulk to nanoparticles, and it further decreased when high pressure was applied to the system. The extent of the reduction in eutectic temperature became more considerable when the excess volume parameter was negative. For the change from bulk to nanoparticles, the eutectic composition moved in the direction 
of the low melting temperature element, B. When applying high pressure, the eutectic composition moved back in the direction of the high melting temperature element, A.

(2) When the interaction parameter of the liquid was $0 \mathrm{~kJ} \mathrm{~mol}^{-1}$, the eutectic temperature decreased during the change from bulk to nanoparticles. It also decreased when high pressure was applied to the system when the liquid had a negative excess volume, whereas it increased when the liquid had a positive excess volume. The observed change in direction of the eutectic temperature is similar to the results obtained when the interaction parameter of the liquid was $-15 \mathrm{~kJ} \mathrm{~mol}^{-1}$.

The present results can indicate a direction for the synthesis of nanoparticles under high pressure and application of nanoparticles under extreme conditions such as high temperature and high pressure.

Author Contributions: Conceptualization, J.L. and G.M.; methodology, J.L. and G.M.; investigation, J.L. and H.G.K.; writing—original draft preparation, J.L. and H.G.K.; writing—review and editing, all authors. All authors have read and agreed to the published version of the manuscript.

Funding: This research was funded by the Ministry of Science and ICT (MSIT), South Korea, grant number NRF-2016K1A3A1A31913031, and by a grant from the Ministry of Science and Technology, Israel. H.G.K was supported by a Korea Institute for Advancement of Technology grant, funded by the Ministry of Trade, Industry and Energy (MOTIE), South Korea, grant number P0002019, as part of the Competency Development Program for Industry Specialists.

Institutional Review Board Statement: Not applicable.

Informed Consent Statement: Not applicable.

Data Availability Statement: The data that support the findings of this study are available from the corresponding author upon reasonable request.

Conflicts of Interest: The authors declare no conflict of interest. The funders had no role in the design of the study; in the collection, analyses, or interpretation of data; in the writing of the manuscript; or in the decision to publish the results.

\section{References}

1. Weissmüller, J. Alloy thermodynamics in nanostructures. J. Mater. Res. 1994, 9, 4-7. [CrossRef]

2. Weissmüller, J.; Bunzel, P.; Wilde, G. Two-phase equilibrium in small alloy particles. Scr. Mater. 2004, 51, 813-818. [CrossRef]

3. Tanaka, T.; Hara, S. Thermodynamic evaluation of binary phase diagrams in small particle systems. Z. Metallkd. 2001, 92, 467-472.

4. Tanaka, T.; Hara, S. Thermodynamic evaluation of nano-particle binary alloy phase diagrams. Z. Metallkd. 2001, 92, 1236-1241.

5. Lee, J.; Mori, H.; Lee, J.; Tanaka, T.; Penttilä, K. Phase diagrams of nanometer-sized particles in binary systems. JOM 2005, 57, 56-59. [CrossRef]

6. Park, J.; Lee, J. Phase Diagram Reassessment of Ag-Au System Including Size Effect. Calphad 2008, 32, 135-141. [CrossRef]

7. Lee, J.; Park, J.; Tanaka, T. Effects of interaction parameters and melting points of pure metals on the phase diagrams of the binary alloy nanoparticle systems: A classical approach based on the regular solution model. Calphad 2009, 33, 377-381. [CrossRef]

8. Lee, J.; Sim, K.J. General Equations of Calphad-type Thermodynamic Description for Metallic Nanoparticle Systems. Calphad 2014, 44, 129-132. [CrossRef]

9. Sim, K.; Lee, J.J. Phase Stability of Ag-Sn Nanoparticles. J. Alloys Compd. 2014, 590, 140-146. [CrossRef]

10. Hillert, M.; Agren, J. Effect of surface free energy and surface stress on phase equilibria. Acta Mater. 2002, 50, 2429-2441. [CrossRef]

11. Shirinyan, A.S.; Gusak, A.M. Phase diagrams of decomposing nanoalloys. Phil. Mag. 2004, 84, 579-593. [CrossRef]

12. Shirinyan, A.S.; Gusak, A.M.; Wautelet, M. Phase diagram versus diagram of solubility: What is the difference for nanosystems? Acta Mater. 2005, 53, 5025-5032. [CrossRef]

13. Li, M.; Zhu, T.-S. Modeling the melting temperature of nanoscaled bimetallic alloys. Phys. Chem. Chem. Phys. 2016, 18, 16958-16963. [CrossRef] [PubMed]

14. Kaptay, G. Nano-Calphad: Extension of the Calphad method to systems with nano-phases and complexions. J. Mater. Sci. 2012, 47, 8320-8335. [CrossRef]

15. Lee, J.; Nakamoto, M.; Tanaka, T. Thermodynamic Study on the Melting of Nanometer-sized Gold Particles on Graphite Substrate. J. Mater. Sci. 2005, 40, 2167-2171. [CrossRef]

16. Lee, J.; Tanaka, T.; Lee, J.; Mori, H. Effect of substrates on the melting temperature of gold nano particles. Calphad 2007, 31, 105-111. [CrossRef]

17. Lee, J.; Lee, J.; Tanaka, T.; Mori, H. In-situ atomic scale observation of melting point suppression in nanometer-sized gold particles. Nanotechnology 2009, 20, 475706. [CrossRef] [PubMed] 
18. Guenther, G.; Guillon, O. Models of size-dependent nanoparticle melting tested on gold. J. Mater. Sci. 2014, 49, 7915-7932. [CrossRef]

19. Tang, C.; Sung, Y.-M.; Lee, J. Nonlinear size-dependent melting of the silica-encapsulated silver nanoparticles. App. Phys. Lett. 2012, 100, 201903.

20. Monji, F.; Jabbareh, M.A. Thermodynamic model for prediction of binary alloy nanoparticle phase diagram including size dependent surface tension effect. Calphad 2017, 58,1-5. [CrossRef]

21. Guisbiers, G.; Mendoza-Cruz, R.; Bazán-Díaz, L.; Velázquez-Salazar, J.J.; Mendoza-Perez, R.; Robledo-Torres, J.A.; RodriguezLopez, J.-L.; Montejano-Carrizales, J.M.; Whetten, R.L.; José-Yacamán, M. Electrum, the Gold-Silver Alloy, from the Bulk Scale to the Nanoscale: Synthesis, Properties, and Segregation Rules. ACS Nano 2016, 10, 188-198. [CrossRef]

22. Zhao, N.; He, Y.Q.; Yang, C.C. A new approach to construct bulk and size dependent continuous binary solution phase diagrams of alloys. RSC Adv. 2015, 5, 96323-96327. [CrossRef]

23. Zhao, Z.; Fisher, A.; Cheng, D. Phase diagram and segregation of Ag-Co nanoalloys: Insights from theory and simulation. Nanotechnology 2016, 27, 115702. [CrossRef]

24. Delsante, S.; Borzone, G.; Novakovic, R.; Piazza, D.; Pigozzi, G.; Janczak-Rusch, J.; Pilloni, M.; Ennas, G. Synthesis and thermodynamics of Ag-Cu nanoparticles. Phys. Chem. Chem. Phys. 2015, 17, 28387-28393. [CrossRef]

25. Sopoušek, J.; Zobač, O.; Buršík, J.; Roupcová, P.; Vykoukal, V.; Brož, P.; Pinkas, J.; Vřešt'ál, J. Heat-induced spinodal decomposition of Ag-Cu nanoparticles. Phys. Chem. Chem. Phys. 2015, 17, 28277-28285. [CrossRef]

26. Jabbareh, M.A.; Monji, F. Thermodynamic modeling of Ag-Cu nanoalloy phase diagram. Calphad 2018, 60, 208-213. [CrossRef]

27. Delsante, S.; Novakovic, R.; Borzone, G. Synthesis, characterization and thermal stability of SnAg and SnAgCu nanoparticles. J. Alloys Compd. 2018, 747, 385-393. [CrossRef]

28. Roshanghias, A.; Vrestal, J.; Yakymovych, A.; Richter, K.W.; Ipser, H. Sn-Ag-Cu nanosolders: Melting behavior and phase diagram prediction in the Sn-rich corner of the ternary system. Calphad 2015, 49, 101-109. [CrossRef]

29. Sopousek, J.; Vrestal, J.; Zemanova, A.; Bursik, J. Phase diagram prediction and particle characterization of Sn-Ag nano alloy for low melting point lead-free solders. J. Min. Metall. Sect. B. 2012, 48, 419-425. [CrossRef]

30. Bao, T.T.; Kim, Y.; Lee, J.; Lee, J.-G. Preparation and Thermal Analysis of Sn-Ag Nano Solders. Mater. Trans. 2010, 51, 2145-2149. [CrossRef]

31. Guisbiers, G.; Mejia-Rosales, S.; Khanal, S.; Ruiz-Zepeda, F.; Whetten, R.L.; José-Yacaman, M. Gold-Copper Nano-Alloy, "Tumbaga", in the Era of Nano: Phase Diagram and Segregation. Nano Lett. 2014, 14, 6718-6726. [CrossRef]

32. Braidy, N.; Purdy, G.R.; Botton, G.A. Equilibrium and stability of phase-separating Au-Pt nanoparticles. Acta Mater. 2008, 56, 5972-5983. [CrossRef]

33. Wilde, G.; Bunzel, P.; Rösner, H.; Weissmüller, J. Phase equilibria and phase diagrams of nanoscaled systems. J. Alloys Compd. 2007, 434-435, 286-289. [CrossRef]

34. Dahan, Y.; Makov, G.; Shneck, R.Z. Nanometric size dependent phase diagram of Bi-Sn. Calphad 2016, 53, 136-145. [CrossRef]

35. Jesser, W.A.; Shiflet, G.J.; Allen, G.L.; Crawford, J.L. Equilibrium phase diagrams of isolated nano-phases. Mater. Res. Innovat. 1999, 2, 211-216. [CrossRef]

36. Shirinyan, A.; Wilde, G.; Bilogorodskyy, Y. Solidification loops in the phase diagram of nanoscale alloy particles: From a specific example towards a general vision. J. Mater. Sci. 2018, 53, 2859-2879. [CrossRef]

37. Cui, M.; Lu, H.; Jiang, H.; Cao, Z.; Meng, X. Phase Diagram of Continuous Binary Nanoalloys: Size, Shape, and Segregation Effects. Sci. Rep. 2017, 7, 41990. [CrossRef]

38. Zhao, Z.; Wang, F.-H.; Fisher, A.; Shen, Y.; Cheng, D. Phase stability and segregation behavior of nickel-based nanoalloys based on theory and simulation. J. Alloys Compd. 2017, 708, 1150-1160. [CrossRef]

39. Guisbiers, G.; Khanal, S.; Ruiz-Zepeda, F.; Roque de la Puente, J.; José-Yacaman, M. Cu-Ni nano-alloy: Mixed, core-shell or Janus nano-particle? Nanoscale 2014, 6, 14630-14635. [CrossRef]

40. Sopousek, J.; Vrestal, J.; Pinkas, J.; Broz, P.; Bursik, J.; Styskalik, A.; Skoda, D.; Zobac, O.; Lee, J. Cu-Ni nanoalloy phase diagram-Prediction and experiment. Calphad 2014, 45, 33-39. [CrossRef]

41. Shirinyan, A.S. Two-phase equilibrium states in individual $\mathrm{Cu}-\mathrm{Ni}$ nanoparticles: Size, depletion and hysteresis effects. Beilstein J. Nanotechnol. 2015, 6, 1811-1820. [CrossRef] [PubMed]

42. Pavan, L.; Baletto, F.; Novakovic, R. Multiscale approach for studying melting transitions in CuPt nanoparticles. Phys. Chem. Chem. Phys. 2015, 17, 28364-28371. [CrossRef]

43. Ghasemi, M.; Zanolli, Z.; Stankovski, M.; Johansson, J. Size- and shape-dependent phase diagram of In-Sb nano-alloys. Nanoscale 2015, 7, 17387-17396. [CrossRef] [PubMed]

44. Kroupa, A.; Káňa, T.; Buršík, J.; Zemanová, A.; Šob, M. Modelling of phase diagrams of nanoalloys with complex metallic phases: Application to Ni-Sn. Phys. Chem. Chem. Phys. 2015, 17, 28200-28210. [CrossRef]

45. Bonham, B.; Guisbiers, G. Thermal stability and optical properties of Si-Ge nanoparticles. Nanotechnology 2017, $28,245702$. [CrossRef] [PubMed]

46. Bajaj, S.; Haverty, M.G.; Arróyave, R.; Goddard III FRSC, W.A.; Shankar, S. Phase stability in nanoscale material systems: Extension from bulk phase diagrams. Nanoscale 2015, 7, 9868-9877. [CrossRef]

47. Asadikiya, M.; Sabarou, H.; Chen, M.; Zhong, Y. Phase diagram for a nano-yttria-stabilized zirconia system. RSC Adv. 2016, 6, 17438-17445. [CrossRef] 
48. Drazin, J.W.; Castro, R.H.R. Phase Stability in Nanocrystals: A Predictive Diagram for Yttria-Zirconia. J. Am. Ceram. Soc. 2015, 98, 1377-1384. [CrossRef]

49. Guenther, G.; Theissmann, R.; Guillon, O. Size-Dependent Phase Transformations in Bismuth Oxide Nanoparticles. II. Melting and Stability Diagram. J. Phys. Chem. C 2014, 118, 27020-27027. [CrossRef]

50. Kim, S.S. Thermodynamic modeling of the $\mathrm{CeO}_{2}-\mathrm{CoO}$ nano-phase diagram. J. Alloys Compd. 2014, 588, 697-704. [CrossRef]

51. Cheng, Y.; Su, H.; Koop, T.; Mikhailov, E.; Pöschl, U. Size dependence of phase transitions in aerosol nanoparticles. Nat. Commun. 2015, 6, 5923. [CrossRef]

52. Lu, H.; Meng, X. Nanophase diagram of binary eutectic Au-Ge nanoalloys for vapor-liquid-solid semiconductor nanowires growth. Sci. Rep. 2015, 5, 11263. [CrossRef]

53. Koto, M. Thermodynamics and kinetics of the growth mechanism of vapor-liquid-solid grown nanowires. J. Cryst. Growth 2015, 424, 49-54. [CrossRef]

54. Schwalbach, E.J.; Voorhees, P.W. Phase Equilibrium and Nucleation in VLS-Grown Nanowires. Nano Lett. 2008, 8, 3739-3745. [CrossRef]

55. Adhikari, H.; Marshall, A.F.; Goldthorpe, I.A.; Chidsey, C.E.D.; McIntyre, P.C. Metastability of Au-Ge Liquid Nanocatalysts: Ge Vapor-Liquid-Solid Nanowire Growth Far below the Bulk Eutectic Temperature. ACS Nano 2007, 1, 415-422. [CrossRef] [PubMed]

56. Ben Shalom, S.; Kim, H.G.; Emuna, M.; Argaman, U.; Greenberg, Y.; Lee, J.; Yahel, E.; Makov, G. Anomalous pressure dependent phase diagram of liquid Ga-In alloys. J. Alloys Compd. 2020, 822, 153537. [CrossRef]

57. Kim, H.G.; Lee, J.; Makov, G. Thermodynamic Calculation of Bi-Sn Alloy Phase Diagram Under Pressure with Advanced Density Measurements. Met. Mater. Int. 2020, 26, 586-590. [CrossRef]

58. Emuna, M.; Greenberg, Y.; Hevroni, R.; Korover, I.; Yahel, E.; Makov, G. Phase diagrams of binary alloys under pressure. J. Alloys Compd. 2016, 687, 360-369. [CrossRef]

59. Kirshon, Y.; Ben Shalom, S.; Emuna, M.; Greenberg, Y.; Lee, J.; Makov, G.; Yahel, E. Thermophysical Measurements in Liquid Alloys and Phase Diagram Studies. Materials 2019, 12, 3999. [CrossRef]

60. Lee, J.; Schuh, C.A.; Luo, J.; Zhong, Y. Forword: Thermodynamics of nanomaterials. Calphad 2019, 65, 402. [CrossRef]

61. Tolbert, S.H.; Alivisatos, A.P. Size Dependence of a First Order Solid-Solid Phase Transition: The Wurtzite to Rock Salt Transformation in CdSe Nanocrystals. Science 1994, 265, 373-376. [CrossRef] [PubMed]

62. Qadri, S.B.; Yang, J.; Ratna, B.R.; Skelton, E.F.; Hu, J.Z. Pressure Induced Structural Transitions in Nanometer Size Particles of PbS. Appl. Phys. Lett. 1996, 69, 2205-2207. [CrossRef]

63. Wang, Z.; Saxena, S.K.; Pischedda, V.; Liermann, H.P.; Zha, C.S. X-Ray Diffraction Study on Pressure-Induced Phase Transformations in Nanocrystalline Anatase/rutile $\left(\mathrm{TiO}_{2}\right)$. J. Phys. Condens. Matter. 2001, 13, 8317-8323. [CrossRef]

64. Daou, T.J.; Pourroy, G.; Bégin-Colin, S.; Grenèche, J.M.; Ulhaq-Bouillet, C.; Legaré, P.; Bernhardt, P.; Leuvrey, C.; Rogez, G. Hydrothermal Synthesis of Monodisperse Magnetite Nanoparticles. Chem. Mater. 2006, 18, 4399-4404. [CrossRef]

65. Hsu, Y.-J.; Gordeeva, A.; Antlauf, M.; Häussermann, U.; Andersson, O. Development of a high pressure stirring cell up to 2 GPa: A new window for chemical reactions and material synthesis. High Press. Res. 2020, 40, 358-368. [CrossRef]

66. Makov, G.; Emuna, M.; Yahel, E.; Kim, H.G.; Lee, J. Effect of pressure on the interactions and phase diagrams of binary alloys. Comp. Mat. Sci. 2019, 169, 109103. [CrossRef]

67. Iida, T.; Guthrie, R.I.L. The Physical Properties of Liquid Metals; Oxford University Press Inc.: New York, NY, USA, 1993 ; pp. 10-11.

68. Hack, K. The SGTE Casebook, 2nd ed.; Woodhead Publishing Limited: Cambridge, UK, 2008; pp. 50-55.

69. Pelton, A.D. Phase Diagrams and Thermodynamic Modeling of Solutions; Elsevier: Amsterdam, The Netherlands, 2019; pp. 108-110. 